\title{
RETRATO DE OCTAVIO PAZ
}

\author{
Enrico Mario Santí
}

E ntrevisté a Octavio Paz muchas veces a lo largo de los casi veinte años que trabajamos juntos. Las nuestras eran conversaciones que casi siempre versaban sobre su vida y su obra, y en especial sobre aquellos textos suyos, como Libertad bajo palabra y El laberinto de la soledad, que me tocó preparar para ediciones anotadas y comentadas. Sostuvimos la presente a fines de 1996. La ocasión fue un diálogo que, como parte del libro Retrato de Octavio Paz, la editorial Galaxia-Gutenberg de Barcelona me encomendó oportunamente. Como ese libro es de inminente publicación, agradezco doble y especialmente a la editorial, a su director Joan Tarrida, y a mi buen amigo Nicanor Vélez el permiso de darla a conocer ahora y la confianza que ello supone. Los problemas de salud de Paz posteriores a nuestro encuentro le impidieron revisar y corregir, como solía hacer, su transcripción. En mi esfuerzo por ponerla al día, pedí a Marie-José Paz, viuda del poeta, que me ayudara en su corrección. Sin la eficiente y sesuda intervención de Marie-José el presente texto no habría sido posible.

EnRICO MARIo SANTí (Santiago de Cuba, 1950) ocupa actualmente la cátedra William T. Bryan de Estudios Hispánicos en la Universidad de Kentucky, Lexington. Entre sus libros se destacan Pablo Neruda: The Poetics of Prophecy (1982), la edición crítica del Canto General (1991), El Acto de las Palabras: Estudios y Diálogos con Octavio Paz (1998) y Bienes del Siglo: Sobre Cultura Cubana (2002). 
Recuerdo que en aquella ocasión que conversamos en la biblioteca de su casa del Paseo de la Reforma, Paz no se sentía del todo bien. A su molestia física se unía, en ese momento, un persistente disgusto moral ante la realidad mexicana y sus discordias políticas, como reflejan los pasajes finales de nuestra conversación. A más de cinco años de habérsele otorgado el Premio Nobel, no había día en que la prensa local no publicara un ataque, crítica o vejación de sus opiniones, y a veces de su persona, casi siempre de manera gratuita. Además de ajustarse a las normas editoriales encomendadas, nuestro diálogo siguió las partes de una agenda de mutuo acuerdo. Por eso, para los que conocen las previas y muchas entrevistas que concedió el poeta, gran parte de la nuestra les resultará familiar. Acaso los pasajes más innovadores —o al menos, los que más me gustan - son aquellos donde pudimos hablar sobre sus orígenes poéticos: su lectura de Quevedo, por ejemplo; y en el otro extremo, su difícil debate con la clase intelectual mexicana, a diferencia del diálogo con el país y su pueblo, que era, y sigue siendo, fructífero.

No dejan de resonar sus palabras de entonces hoy, ocho años después, cuando la figura de Paz sigue siendo el objeto de críticas, algunas no tan veladas, incomprensiones y hasta ninguneos anacrónicos. En un reciente coloquio sobre la obra de Paz en el Colegio de México en el que me tocó participar, por ejemplo, distinguidos científicos sociales de la talla de los doctores Soledad Loaeza y José Woldenberg porfiaron en que, en el célebre discurso de Frankfurt de octubre de 1984, conocido por su título de "El diálogo y el ruido", Paz había excluido el papel de Estados Unidos de su crítica al entonces proceso de paz en Centroamérica, cuando lo cierto es que esa crítica al gobierno de Ronald Reagan aparece en al menos tres pasajes distintos del discurso; o bien en que, en el mismo texto, Paz había sido injusto con el gobierno sandinista al llamarlo una dictadura burocraticomilitar al estilo de la de Cuba*.

* Entre el 19 de julio de 1979, cuando los sandinistas asumieron el poder en Managua, y noviembre de 1984, cuando se celebran las primeras elecciones después de la revolución nicaragüense, el gobierno sandinista confiscó todas las estaciones de televisión, cerró múltiples veces La Prensa, el único periódico de oposición, y muchas veces mandó quemar sus ejemplares; ignoró consistentemente el célebre Estatuto de Derechos y Garantías que consagra el derecho a la organización política; conculcó el derecho del líder sindicalista Fabio Gadea a abrir una estación de televisión independiente y cerró tres de sus estaciones de radio; creó los Comités de Defensa de la Revolución al estilo de los CDR cubanos; votó en contra de la condena de la ONU a la invasión soviética de Afganistán; estableció convenios con los partidos comunistas de todos los países del bloque soviético; pospuso las elecciones nacionales por lo menos cinco años; prohibió varias veces la reunión masiva del MDN (Movimiento Democrático Nicaragüense); prohibió las encuestas independientes a raíz de una que les daba a los sandinistas (en noviembre de 1980) un margen de apoyo de sólo 28\%; asesinó a por lo 
En días en que Paz el pensador se plagia, el poeta se invoca, y el hombre público que fue se tergiversa, tal vez valga la pena recordar estas palabras suyas en que recordó tantas cosas sobre su vida y su obra, su tierra y su gente.

\section{ENTREVISTA}

\section{Una familia de escritores}

ENRICO MARIO SANTí: En otras entrevistas has hablado de tus primeros recuerdos literarios.

Octavio Paz: En general, el misterio de la vocación (porque es un misterio) tiene que ver con la infancia. La vocación se manifiesta en la juventud, pero hay un período de imitación, diríamos, de modelos familiares. En mi caso fue decisiva la presencia de mi abuelo, Ireneo Paz, que era escritor. Yo lo veía leer y escribir todos los días. Sabía que había escrito memorias, novelas, de modo que fue un poco el modelo. Sí, efectivamente, en mi casa, de niño, había una gran influencia del mundo de la literatura. Mi abuelo tenía una buena biblioteca. Pero también tenía unos atriles con fotografías de autores de la época. Ahí podías ver fotos, o bien grabados, por ejemplo, de Víctor Hugo y otros escritores franceses. Pero no solamente franceses, también había hispanoamericanos, mexicanos... Estaba Pérez Galdós, que era uno de sus modelos.

EMS: ¿Norteamericanos?

OP: Whitman, no: creo que es de adelantada, y tal vez era muy radical. Emerson sí, probablemente; también Longfellow.

EMS: ¿Pero con tu abuelo hablaste de literatura alguna vez?

OP: Cómo no, muchas veces. Me contaba historias. Yo lo veía leer, y cuando veía que agarraba los libros, por ejemplo cuando leía a Quevedo, yo también quería leer a Quevedo. Naturalmente no entendía nada.

EMS: ¿Él te veía también a ti como escritor?

OP: No. Yo, al principio, tuve la mayor libertad, de niño, para leer los libros que se me antojaran. Nadie se preocupó, sea por tolerancia o por descuido, en saber lo que leía. De modo que mis primeras revelaciones

menos 35 indios miskitos en la masacre de Cruce de las Balsas y después abrió una serie de campos de concentración para el resto de la tribu; clausuró la estación Radio Católica bajo cargos de difamación al gobierno; prohibió que la escuela católica La Salle contratara a sus propios profesores. Estos y muchos otros hechos, que prueban que Octavio Paz no exageraba la comparación del gobierno sandinista con el de Cuba, se pueden comprobar en el libro Nicaragua's Continuing Revolution, 1977-1990: A Chronology, ed. David Ridenour y David Amalsi (1990), pp. 44-255. 
eróticas se las debo a la literatura. Leí muchas novelas que no tenía por qué haber leído a esa edad.

EMS: También está tu padre que fue periodista e historiador.

OP: Sí, bueno, mucho menos, porque mi relación con él fue menos íntima en la infancia. Él no estaba en la casa y había grandes ausencias.

EMS: Pero esas cosas funcionan también de manera inconsciente, ¿no? Es decir, sabías que tu padre era escritor.

OP: No solamente eso. Le ayudé cuando adolescente a copiar a máquina artículos o textos suyos de memorias de la Revolución Mexicana, incluso textos de placer, a veces un poco desde el punto de vista literario. Pero fue menor la influencia de mi padre, mucho mayor la de mi abuelo, y después, también, una influencia determinante fue la de una tía.

EMS: ¿Tu tía Amalia?

OP: Sí, era gran lectora, le interesaba mucho la literatura. Pero no tradujo a Baudelaire, como tú me preguntaste hace un momento.

EMS: ¿Pero sí era una amante de la poesía francesa?

OP: Era una amante de la novela, más que de la poesía francesa. Pero conocía bien la poesía, sobre todo de lengua española. Tenía un álbum, yo lo he contado en un prólogo de estas Obras completas que hemos publicado en Círculo de Lectores. Tenía un álbum y había muchos poemas de amigos suyos, poetas de la época. Entre ellos, y nada menos, un poema de Gutiérrez Nájera.

EMS: ¿Dedicado a ella?

OP: Dedicado a ella.

EMS: ;Versos de circunstancia!

OP: Desde los románticos, posiblemente desde Bécquer, tal vez antes, se escribían poemas para las señoritas de la época en un álbum muy decorado con una escritura peculiar, y con ilustraciones, dibujos de pájaros o de paisajes. Era un gusto muy fin de siglo. El de mi tía Amalia era inmediatamente anterior a la Revolución, anterior a 1910: un álbum que abarca de 1880 a 1900, más o menos. Todavía lo conservo.

EMS: Pero, aparte del álbum, ¿hablabas tú con tu tía Amalia acerca de literatura o acerca de poesía, o acerca de tu propia vocación?

OP: Hablaba sobre todo de literatura. De poesía menos. Pero no recuerdo exactamente. Hablaba de mis lecturas más que nada, y sí, creo que le interesaba mucho cuando yo empecé a escribir. Pero ella murió antes de que yo realmente empezara a publicar. Ésas fueron las influencias fundamentales. En el caso de mi madre no fue una influencia literaria, pero sí el descubrimiento del mundo español. Para mí, España, mi descubrimiento de España, tiene dos ventanas: una inmediata, mi madre. Es decir: 
la música española, la cocina española, el mundo hispánico, diríamos, el mundo andaluz.

EMS: Te lo dice también un descendiente de andaluces.

OP: Ahí está. Iba de visita con mis abuelos que habían vivido en un pueblo a una hora de Puerto de Santa María. Mi abuelo era de Medina Sidonia, un lugar cerca de Jerez. Pero la otra ventana, también decisiva, fue la literatura española y la poesía de España. Muy pronto empecé a leer y a hojear libros ilustrados de historia. Creo que de aquí los podemos ver, estos libros rojos que tú ves ahí. Entre esos tomos está la Historia de La Fuente. Todo eso no lo leí, era yo muy niño, pero sí lo hojeaba. De pronto se convirtieron en héroes (curiosamente, más que los héroes españoles) los árabes. Todo ese mundo islámico me sedujo. Todo esto forma parte, diríamos, de mi aprendizaje literario.

EMS: Hay todo un romance familiar literario en esa casa donde te crías.

OP: Sí, exactamente. Era una casa, como he dicho otras veces, con muchos libros, con muebles buenos, viejos. Nunca se compraron muebles en mi casa. Cuando había un mueble que no funcionaba bien, que parecía inutilizado, se le mandaba a reparar.

\section{Un niño en la escuela}

EMS: Tuviste una educación bastante formal, al principio. Por ejemplo, tu kindergarten en Los Ángeles...

OP: La etapa en que estuve en Estados Unidos fue importante. Me marcó para siempre la estancia en Los Ángeles. Después estuve en un colegio francés, El Zacatito, de los hermanos La Salle. Ahí estudié los primeros cuatro años de la primaria. Y en el último año tuve entre mis maestros a un hermano, un profesor al que le llamábamos el hermano Antonio. Nos fascinaba porque nos contaba las leyendas de la historia sagrada de un modo lleno de poesía. Los milagros, todas estas historias de la Biblia que son prodigiosas se las oímos, en versión muy depurada porque la Biblia es un libro bastante arriesgado. Después, ingresé en la segunda época en la escuela. Terminé la educación primaria en una escuela inglesa, el colegio Williams. Ahí, también, me interesó la historia y la literatura. Finalmente, entré a la escuela secundaria. Tuve una gran admiración literaria, en maestras más que en maestros. La primera aparición pública de la mujer en México es en la educación. Tuve maestras admirables que todavía recuerdo con mucho cariño.

EMS: ¿Se trata de tus primeras lecturas serias? 
OP: Sí, de literatura. Tuve una maestra, Soledad Anaya: celosa, muy purista. Le escandalizaba que yo defendiese, un día en la clase, a Góngora. Leía además a los modernistas, a Rubén Darío por ejemplo. Los muchachos de mi edad que empezábamos a escribir ingresamos en la Universidad y tuvimos (al menos yo tuve) una doble iniciación. Por una parte, la iniciación a la vida política de la época, de rebeliones estudiantiles. La crítica del régimen revolucionario de aquellos años. Y junto a eso, la literatura.

EMS: ¿Hasta qué punto se podría decir que esta crítica política, durante tu primera juventud, es una herencia de tu padre?

OP: No. Es una actitud general de la época. Fundamos una unión de estudiantes, pro-obrera y campesina. Pero en el bachillerato, a mis amigos, a todos ellos, les interesaba la literatura. Para nosotros la literatura era inseparable de las visiones políticas.

EMS: ¿Y sociales?

OP: Claro, y fundamentalmente, junto a los hijos de obreros y campesinos. Esto pasaba en el año treinta, cuando yo entré a la escuela preparatoria, al bachillerato. El año anterior había sido el de la gran rebelión estudiantil, asociada a la gran cruzada de José Vasconcelos, nuestro héroe intelectual. Mejor dicho: la gran cruzada que había fracasado. De modo que todos nos sentíamos partícipes de la derrota: de Vasconcelos, de las elecciones que, a nuestro juicio (y era verdad), el contrincante había ganado de modo fraudulento. Es el año en que nace también el Partido Nacional Revolucionario, que después se transforma en el pri. De modo que todo esto fue en 1929. Todo esto era el marco político, pero mucho más el literario.

EMS: Ése es un momento muy importante de la literatura y no solamente en México. En realidad en todo el mundo, en Occidente en general. También has contado, por ejemplo, que fue precisamente durante esos años que en un mismo número de la revista Contemporáneos descubres The Waste Land y Anábasis.

OP: Fue un poquito antes de esto. Quisiera hablar de los maestros que tuvimos. Desde luego Carlos Pellicer, entonces profesor de Literatura Hispanoamericana. Con él realmente empezamos a leer con mayor atención a muchos poetas que conocíamos mal. Por ejemplo a Lugones, y también a los poetas de vanguardia de ese momento.

EMS: ¿Españoles también?

OP: Sí, claro. Es cuando aparecen los poetas españoles, los andaluces. Pero, en fin, antes de esto quería hablarte también de filosofía. Tuvimos varios maestros muy empapados en la fenomenología, la filosofía moderna, grandes lectores de la Revista de Occidente. Entre ellos, en primer término, Samuel Ramos. 


\section{EMS: ¿También era maestro en la preparatoria?}

OP: Sí, justamente. De modo que tuvimos a Pellicer, a Samuel Ramos, a José Gorostiza, aunque estuvo poco tiempo, y a Julio Torri. Ése sí fue mi maestro. Primero en el bachillerato y luego en la Facultad de Filosofía y Letras. Es el momento en que aparecen todas esas nuevas corrientes; para nosotros era la gran novedad. No entendíamos bien lo que pasaba en el mundo. Pero imagínate: estaba, por un lado, la Revista de Occidente. Esto significaba la filosofía alemana, que empezamos a leer muy jóvenes. Al mismo tiempo, los poetas, los novelistas, a quienes leímos muchísimo. Entre los españoles, por ejemplo, y mucho, a Benjamín Jarnés. Y a los poetas de la generación del 27. Teníamos un culto por ellos. Había amigos míos que copiaban a máquina sus poemas, porque no había bastantes ejemplares para leer a Rafael Alberti, o a Pedro Salinas, o a García Lorca. Ahí empezamos a leer a Borges, aunque no nos impresionó demasiado como poeta. Fueron unos diez años después, cuando en Sur Borges empezó a publicar los cuentos de El jardín de senderos que se bifurcan, su primer libro, que nos asombró. Pero eso ya es por los años cuarenta, cuarenta y uno. Tengo todavía la primera edición. Tengo dos ediciones: la mía y otra que me regaló Borges en papel biblia, dedicada.

EMS: En ese momento, ¿también Neruda es el gran poeta?

OP: Digamos que un poco después. Pero ya habíamos leído poemas de Neruda.

EMS: Algunos de ellos en Revista de Occidente.

OP: Algunos poemas de Neruda fueron publicados. Pero no solamente los poetas españoles. En esos años es cuando descubro la novela moderna. Yo había leído a Balzac y a Zola muy joven, de niño también a Dickens. Pero no fue hasta los años de bachillerato que leí a Proust. Para mí fue un estremecimiento, una revelación.

EMS: De ahí viene ese ensayo tuyo que recogimos en Primeras letras.

OP: Leímos también a Kafka, que apareció en español antes que en francés, por ejemplo.

EMS: ¿Y a Joyce?

OP: A Joyce, sí, también. Incluso tuvimos los jóvenes una revista, que se llamó Cuadernos del Valle de México, en cuyo segundo número publicamos un fragmento del Ulises, en una traducción de un chico, amigo nuestro, mexicano. Era significativo todo el estado de inquietudes de ese momento. 
EMS: Se une ahí la preocupación social y política, por una parte, y por la otra, el descubrimiento de una nueva filosofía. También, una nueva poesía y una nueva literatura. Así que ése es un momento clave de tu formación, justamente. ¿Cuántos años tenías entonces?

\section{Un joven en la biblioteca}

OP: Tenía diecisiete, dieciocho, diecinueve. Bueno, eso fue la juventud, hasta los veintitantos años. Leí muchísimo. Pero, también, desde niño había leído a los clásicos españoles. El teatro de Calderón, de Lope de Vega y de Tirso. Y en esa época, leí mucho, por influencia de la generación del 27, a Góngora. Pero me deslicé hacia Quevedo, que me interesó mucho más.

EMS: "Nada me desengaña / el mundo me ha hechizado." Ése es el gran lema que repites constantemente en esa primera época.

OP: Hay un problema, y es éste. En esa etapa leí una serie de poemas, que, en realidad, forman un solo poema que le llaman ahora Heráclito cristiano, a imitación de la de David. Pero en la versión que yo leí, que también fue corregida por Quevedo, se llama Lágrimas de un penitente. Para mí fue una revelación. Claro, tú comparas ese poema con los grandes poemas de la época, con la Fábula de Polifemo y Galatea, pues, es mucho más perfecto el poema de Góngora, que es uno de los grandes poemas europeos del siglo xvii. No es la perfección, la belleza puramente o la hermosura en un poema, como regla general, lo que nos puede impresionar más. Hay otras cosas. Por ejemplo, en la poesía latina los versos no tienen la perfección de Horacio o de Virgilio, pero tienen alguna nota profundamente personal, profundamente moderna que nos toca más de cerca. Ezra Pound, sobre todo, nos da una versión más o menos de un poema que no es una traducción, sino una recreación, diríamos. A mí, en el caso de Quevedo, me ocurrió lo mismo. Toda mi vida he tenido un diálogo con Quevedo.

EMS: ¿Te sigue pareciendo que es el primer poeta moderno?

OP: Sí, creo que en Lágrimas de un penitente, o Heráclito cristiano, aparece esto que me parece esencial: la conciencia enamorada de sí misma. Ahora bien, esto que es un lugar común cristiano, en Quevedo tiene una exasperación que va a ser cada vez más neta, cada vez más clara, cada vez más definitiva, en los sucesores, sobre todo en el siglo diecinueve. Está, por ejemplo, en Baudelaire: la conciencia del mal. 
EMS: Entonces, así como vas descubriendo la poesía moderna, vas descubriendo, tácitamente, una raíz hispánica moderna, que no es precisamente contemporánea, pero sí moderna.

OP: Quevedo es uno de los pocos escritores clásicos españoles que me ha dado esa modernidad. Pero es muy curioso: en España los otros poetas no leyeron a Quevedo como yo lo leí, desde la perspectiva que yo lo leí. El único que podría aproximarse a mi lectura es Neruda, pero no exactamente de la misma manera.

EMS: Tampoco Borges. Borges se opone al gongorismo de la época a través de la relectura de Quevedo.

OP: Nada más que un poco miope, diríamos. Borges vio en Quevedo a un gran retórico, un gran conceptista. Por ejemplo, su lectura del soneto al Duque de Osuna. "Y su epitafio la sangrienta..." Esto es muy hermoso, pero es retórico, una imagen retórica. Para mí lo importante no es eso. Es un poema sobre la envidia, sobre la suerte de los héroes. Está enraizado con la suerte de Escipión. Todo eso, el aspecto propiamente moral de Quevedo, no le interesó a Borges, como tampoco le interesó el aspecto propiamente metafísico.

EMS: Es interesante. Se podría hacer una antología de cómo leen a Quevedo Octavio Paz, Borges y Neruda. Cada uno tiene su Quevedo. Paz, la lectura moral y metafísica; Borges, la lectura retórica; Neruda, la lectura apasionada.

OP: También palpó la muerte.

EMS: También la muerte es parte de esa pasión. Y Lezama Lima ¿cuál sería su lectura?

OP: La de Lezama Lima es un poco también la de Borges. Lo que le interesa, sobre todo, es el sistema de metáforas, que es notable, ¿no? A mí me sorprendió mucho, por ejemplo, que cuando Quevedo habla de la risa, habla de relámpagos, de "risas carmesíes". Es un verso que podría haber sido de Góngora, en cierto modo. Claro, estamos hablando de la vocación poética, de la tentación revolucionaria, y habría que hablar también de la tentación religiosa, que se confunde con la metafísica y con la filosofía. También, por eso, me interesó Quevedo, porque es un poeta religioso negativamente. Es decir, yo no podría aspirar a tener la sublimidad de San Juan de la Cruz, que es el poeta de la unión con Dios. Pero Quevedo es el poeta de la separación de Dios. Y es un poeta muy moderno, lo cual a mí me afectó profundamente, quizá, por razones personales, en mi biografía intelectual, si tú quieres.

Después hay otro tema esencial, en mi poesía y en mi vida: la mujer. 
EMS: Como para todo joven, ¿no? Es muy importante la presencia o la aparición de la mujer.

OP: Caminábamos sin cesar por la ciudad de México en busca de mujeres, esperando a la mujer, que nunca iba a aparecer, o bien iba a aparecer al doblar la esquina o al subir al tranvía.

EMS: Es decir, ya eran surrealistas sin saberlo, porque eso es lo primero que se pregunta André Breton en Nadja.

OP: El encuentro.

EMS: Que no es realmente una cuestión literaria, sino una cuestión vital.

OP: Vital, es lo que digo. Bueno, la separación de Dios en Quevedo tampoco es puramente literaria, tiene una dimensión humana.

EMS: Eso es lo interesante siempre. Después de haber conocido a muchos escritores, después de haber yo mismo escrito poemas, descubrimos que la verdadera poesía es la que se basa en esas profundas experiencias vitales.

OP: Y no bastan las experiencias.

EMS: Tampoco, es cierto.

OP: Pero sin ellas, hay simplemente retórica. Borges usa esas experiencias porque experimentó la tentación de la identidad propia, es decir, la fábula del espejo: ¿quién soy yo? También, la tentación de la eternidad y del infinito. Todo eso en él fue decisivo. En Neruda fueron otras cosas. En mi caso, yo creo que podríamos decir que fueron estas cosas de mi juventud: la revolución, la idea de que podíamos cambiar el mundo, el heroísmo. Y, claro está, la idea de la muerte, de mi alma mortal en este mundo.

\section{El poeta en la calle}

EMS: Todo esto contribuye al momento en que empiezas a escribir.

OP: La poesía fue una manera de darme cuenta de lo que yo quería decir. Muchas veces te acercas al papel atraído por una necesidad oscura de decir algo, pero no sabes qué vas a decir. Eso se nota, por ejemplo, cuando uno quiere escribir un ensayo. Cuando uno va a escribir un poema, muchas veces no sabe qué va a decir. Sientes la necesidad, pero es una necesidad que no aciertas a definir claramente. En su lugar hay una suerte de páramo angustioso. Pero de pronto una chispa, una espiga, un chorro de agua, lo que sea, te lleva a decir ciertas cosas.

EMS: Me recuerda esto mucho al comienzo de tu poema Blanco, donde aparece un girasol y, de pronto, comienza a florecer la palabra. 
OP: Pero en Blanco, más o menos, yo sabía lo que iba a decir. No lo sabía claramente, porque uno nunca sabe lo que va a decir. En otras ocasiones no es así. Por ejemplo, los primeros treinta o cincuenta versos (no sé cuántos serían ahora en este momento), de Piedra de sol, que me fueron absolutamente dictados. Me salieron endecasílabos, perfectamente medidos, y como si yo estuviese repitiendo o transcribiendo algo que estaba oyendo dentro de mí. Estaba yo muy complacido porque eran puras ideas, imágenes que yo podía ver u oír. Las oía con gran placer. Me gustaban y no sabía adónde iban, y entonces tenía deseos de saber cómo iba a continuar esta corriente. Y por eso la imagen del río, y de los árboles. Después me di cuenta de que, aunque lo había escrito en México, en realidad estaba recordando, sin darme cuenta, ciertos momentos de contemplación al caminar al lado del Sena, no el Sena de París sino el de los alrededores de París. Otras veces no es así. Otras veces has preparado el poema, lo has pensado (por ejemplo Blanco), pero de pronto, en el momento de ejecutarlo, surge otra cosa, totalmente distinta. Esto ocurre también en los poemas breves y en los de extensión media. Siempre hay esta colaboración, diríamos, entre la conciencia y lo que llamamos inspiración.

EMS: Aunque podría también llamarse el inconsciente, de alguna manera.

OP: Pero el inconsciente quizás sea una palabra demasiado fácil.

\section{Edición de autor}

EMS: Es interesante, Octavio, que ahora estés haciendo una edición de las Obras completas para Círculo de Lectores.

OP: Bueno, los diez primeros tomos. Me arrepiento mucho de esos diez tomos, que podrían haberse reducido a un tercio, probablemente. Ahora empezamos a publicar la Obra poética, dos tomos de quinientas páginas cada uno. Aparece el primer tomo, que es el volumen que publicó SeixBarral como Obra poética. Después, el segundo tomo va a incluir lo que he escrito después de El mono gramático, y hasta ahora. También, algunos poemas escritos en colaboración, un experimento importante como, por ejemplo, Renga, o el libro escrito con Tomlinson, o bien otro que escribí en la India, que me gusta bastante. Finalmente, las traducciones. Considero que en mi caso no son meras traducciones, sino recreaciones poéticas. Hay algunas traducciones que me gustan, tanto o más que lo mejor que yo he escrito. Por ejemplo, ciertos poemas de Pessoa o bien ciertas libertades que me he tomado con una traducción de originales que yo ignoro. Ignoro, por 
ejemplo, el chino y el japonés; pero a través de versiones al inglés, al francés y a otros idiomas, he podido rehacer ciertos poemas en español. Con algunos de ellos estoy contento. Lo mismo con los sonetos de Nerval, o con algún poema de John Donne. Todo eso va en el segundo tomo junto con los poemas que he escrito después de El mono gramático, es decir, después de 1975, la obra final.

EMS: ¿Incluye tus primeros poemas?

OP: No. Después, hay un volumen que se llama, no tiene todavía un título claro, pero por el momento se va a llamar Primeros escritos. En eso se ha empeñado el editor. A mí no me acaba de gustar, pero está dividido en dos partes: una, el libro que hicimos contigo, en el que tú ayudaste, fuiste definitivo en eso, Primeras letras, y antes, los poemas. Es un librito de unas ciento cincuenta páginas, más o menos, que se llama Primera instancia. Ahí están los poemas inéditos, los que escribí cuando tenía diecisiete años. Estuve dudando mucho. Me dije: ¿Publico esto o no? Mi primera idea fue no publicarlo, pero me ocurrió esto. La edición se llama Obras completas: parecía desleal no publicarlo. Después me di cuenta de que si no lo publicaba yo, lo iban a publicar otros más tarde, que es lo que le ha pasado a Borges y lo que le ha pasado a mucha gente, a muchos poetas. Mejor atreverse y con un poco de impudicia probablemente. En eso tengo el precedente de Neruda y de otros poetas. Voy a publicar los primeros poemas sin alterar los géneros. Hay alteraciones, pero no son de ahora, son antiguas. Es decir, no tal como aparecieron - te voy a explicar eso. En algunos casos, hay una primera versión, pero de esos años, es decir, de la misma época, en que hay pequeñas modificaciones, o raras modificaciones. Son poemas escritos entre 1931, cuando tenía diecisiete años, y 1943, cuando tenía veintinueve. Te voy a explicar por qué hay esa ruptura: la primera parte está compuesta por poemas que nunca han sido recogidos, casi todos publicados en periódicos, por ejemplo El Nacional.

EMS: ¿Como el famoso "Cabellera"?

OP: Sí, hay otro más que no recogieron, que está en El Nacional también. Se trata de poemas publicados en Barandal, una revista que hacíamos en aquella época, en Cuadernos del Valle de México, y en otras más. Son una serie de poemas y tres o cuatro inéditos. Bueno, a mí me gustan, me divierten, son juguetes. Me divirtió verlos.

EMS: ¿Eran juguetes cuando los escribiste?

OP: Más bien, desafíos. Porque estaba yo contagiado por la poética del momento. Había que hablar del patín, del tenis, del deporte. Luego hay este pequeño libro, que es el más débil, a mi juicio, Luna silvestre, donde todavía hay algún verso que podría salvarse. Pero, en fin, hay que publicar- 
lo todo. Después, todo el libro A la orilla del mundo, lo primero que publiqué que, realmente, ya tiene cierto interés, del cual me avergüenzo por la imperfección, pero no por lo que está detrás: la imperfección que es "Raíz del hombre" o "Bajo tu clara sombra", todos esos poemas. Y después, está otra sección de poemas sobre España, dos nada más porque el tercero está en el otro tomo. Y también, la primera versión de Entre la piedra y la flor, muy distinta a la segunda. Algunos de esos poemas fueron publicados en revistas y algunos en la primera edición de Libertad bajo palabra, que luego retiré. Les he puesto el título original de Vigilias. Son poemas un poco de introspección bajo el signo del análisis íntimo, poemas más bien negros, de soledad, no quevedescos pero sí dentro de esa poesía de reflexión interior. Y termina todo en 1943. Tenía veintinueve años, aunque muchos de los poemas escritos en ese período han pasado al tomo de Obra poética, porque me parece que ésas sí son obras. Otras se quedaron en borradores, se quedaron en intentos, y las publico porque ya todo fue publicado. Si no, lo hubiera destruido, excepto los cuatro primeros poemas inéditos, que me parecen graciosos, como una cabriola de jovencito.

EMS: Me alegro de que todo eso por fin se publique; nos da una imagen mucho más completa de esa primera época. Conocíamos ya bastante bien la prosa, que habíamos publicado. Este es el complemento que faltaba.

OP: Es interesante por dos razones. Primero, porque no las condeno totalmente: las veo con cierta ironía y piedad. Después, porque algunas personas me han criticado con bastante malevolencia que yo he ocultado poemas por razones de orden ideológico, político. No es cierto. Ahora que los voy a publicar, se verá que los poemas ideológicos son muy pocos, y que, además, retiré esos poemas porque, simplemente, no me satisfacían poéticamente. Pero no por ninguna otra razón. Los publico porque no tengo más remedio, pero no me gustaría hacerlo.

\section{Un director de revistas}

EMS: Hablemos ahora acerca de esta época, acerca de estos poemas que publicaste en revistas en las que colaborabas y en algunas que dirigías, por ejemplo, Taller, Barandal, Cuadernos del Valle de México. Eso es impresionante. A lo largo de tu vida has estado íntimamente involucrado también en la creación de revistas. Es el Octavio Paz dedicado, también, a la creación de contextos culturales: a agrupar a gente en la 
creación. Ha sido una contribución positiva al desarrollo humano de las personas. La institución de la revista ha sido tu manera de hacerlo.

OP: Sí, es verdad. Al principio de esas revistas no fui yo el editor. Éramos un grupo de jóvenes. Siempre que un grupo de jóvenes escritores se juntan, quieren modificar al mundo, quieren llegar al cielo, quieren defender el infierno, y lo único que se les ocurre es fundar una revista. Éste ha sido el secreto. Después, la fundación de revistas ha obedecido a razones de orden espiritual y, también, ideológico. Por ejemplo, Taller no la fundé yo, la fundamos con un grupo de amigos.

EMS: Yo no lo veo tanto como una cuestión ideológica, sino más bien de moral poética.

OP: El caso de Taller fue más bien de moral literaria. Era un grupo de jóvenes que no teníamos pleito con la generación inmediatamente anterior, pero sí nos sentíamos distintos. De ahí creamos la revista. Después, me hicieron director a mí porque poco a poco los demás fueron abandonándola. Además, hubo gente que daba dinero pero que pidió que alguno fuese responsable y mis amigos decidieron que yo fuese el responsable. Hicimos doce números. Después, otras revistas en las que he participado, como Letras de México o El hijo pródigo. Fui uno de los redactores. Pero lo hice siempre con mucho interés, con mucho entusiasmo sobre todo. En el caso de El hijo pródigo, en los siete primeros números colaboré activamente. Después me fui del país. Muchos años después, fundé Plural. Ahí sí hubo una moral cívica y espiritual. Creía que el país se asfixiaba, que no había una crítica de la sociedad totalitaria, que los jóvenes rebeldes habían olvidado rebelarse contra las tiranías totalitarias.

EMS: El problema vino después del 68. Aquí en México, me refiero.

OP: Yo esencialmente estuve a favor del 68 en lo que tenía de reforma, en lo que tenía de aspiración democrática. Eso fue lo fundamental y estuvo bien. Lo que no estuvo bien fue la actitud que vino después, con los grupos que siguieron al 68. Algunos de ellos se convirtieron en terroristas. Para mí era urgente desinfectar a toda la cultura mexicana.

EMS: Lo interesante acerca de Plural es que en ese momento hay una revisión histórica de México y de América Latina, un revisionismo histórico.

OP: Hay que decir que me ayudaron varias gentes. Yo solo no habría podido hacerlo.

EMS: Por ejemplo, gente como Cosío Villegas.

OP: Sí, claro, de la generación anterior, o bien, gente joven como José de la Colina o Alejandro Rossi, al final Enrique Krauze. Sobre todo, una defensa de la literatura, de la literatura mejor de México y de América. 
Severo Sarduy empezó a colaborar y todos, creo que todos, los que valían propiamente, como Juan Goytisolo.

EMS: ¿Carlos Fuentes?

OP: Carlos Fuentes fue uno de nuestros colaboradores más constantes. Pero aparte de eso, también quise abrirla a una serie de movimientos nuevos. Por ejemplo, la antropología, el estructuralismo de Lévi-Strauss, la lingüística de Jakobson, la resurrección de una posible nueva vanguardia, como la música de Cage. En fin, poner al día al país. Es lo que quisimos hacer y es lo que hemos querido continuar en Vuelta.

\section{Una defensa de la poesía}

EMS: Este año, 1996, se cumplen los cuarenta años de la primera edición de $\mathrm{El}$ arco y la lira. Aunque es un libro que, en realidad, tú empezaste a escribir antes de 1956.

OP: En el cincuenta y seis lo entregué. Lo terminé antes, creo que en 1955.

EMS: Pero lo habías empezado a escribir en Córcega.

OP: Empecé en el 51, 52, y lo interrumpí porque tuve que viajar a Oriente. Fue el primer viaje. Después continué, pero en cuanto llegué a México en el año 53, seguí, aunque tenía que trabajar. Yo no he vivido de mis libros sino hasta muy tarde. He vivido del trabajo de diplomático. Tenía que trabajar todo el día, y la noche o los weekends dedicarlos a la escritura de poemas, o de El arco y la lira, o del libro que tuviese entre manos.

EMS: Me da la impresión que El arco y la lira es el crisol donde se funden todas tus experiencias poéticas, en el sentido de que todo el conocimiento poético, todo el conocimiento de tus poemas, se viene a resumir, a articular, en ese libro. También creo otra cosa: que los otros libros sobre poética, y sobre la poesía que has escrito a partir del año cincuenta y seis, son reiteraciones.

OP: O ampliaciones.

EMS: $O$ revisiones, o críticas, de ese libro fundamental.

OP: La semilla está en un pequeño ensayo juvenil, "Poesía de soledad y poesía de comunión”, en el que tomo como emblemas a San Juan de la Cruz y a Quevedo. Lo que escribí en El arco y la lira es un desarrollo de todo eso. No sé si ahora escribiría lo mismo que escribí en El arco y la lira. No me arrepiento de haber escrito lo que escribí, aunque ahora me parece una empresa quimérica. 
EMS: Es cierto que El arco y la lira, por ejemplo, es un libro en el que, un poco como en $\mathrm{El}$ laberinto de la soledad, echas mano a otras áreas del conocimiento, como la antropología, o la lingüística o la religión...

OP: O la filosofía. La poesía es una respuesta o bien una expresión de la condición original de los hombres, y luego tiene características especiales que la distinguen esencialmente de la religión, que es otra respuesta de la filosofía... pero es tan legítima como ellas. Eso lo sigo pensando.

EMS: Por eso, entonces, se puede decir que $\mathrm{El}$ arco y la lira, al igual que tus otros textos posteriores, son una defensa de la poesía, en el sentido de que sitúan la poesía en relación con otros, como se dice hoy, discursos, otros modos de pensamiento, otros modos de análisis. Además de que en el momento en que piensas en todas esas cuestiones, la poesía no se considera uno de los discursos legítimos de análisis. Por ejemplo, pensemos en lo que Sartre había escrito sobre Mallarmé o Baudelaire.

OP: Ya Sartre había escrito antes Qu'est-ce que la littérature?, donde hace una crítica de la poesía.

EMS: $Y$ del poeta.

OP: Sartre estaba totalmente equivocado. Pensaba que la poesía no es literatura.

EMS: Ni es comprometida.

OP: No puede serlo, según él, porque la palabra se transforma en objeto, como en el caso de la pintura o de las otras artes, mientras que la prosa, aunque sigue teniendo valores físicos, es fundamentalmente sentido.

EMS: Te tiene que haber turbado enormemente haber leído esto, ¿no?

OP: Sí, bueno, pero no lo creí. Creí desde el principio que era un horror. Sartre estaba, en primer lugar, considerando la poesía desde una perspectiva muy francesa, muy reducida, sobre todo del simbolismo, del surrealismo. Pensaba que había otras aproximaciones.

EMS: Pero lo curioso es cómo, en ese momento, nadie le contestó.

OP: Yo sí le contesté, aunque no directamente.

EMS: Tú sí, pero yo digo sus contemporáneos, por ejemplo, Merleau-Ponty nunca le contestó.

OP: Estaba de acuerdo con él...

EMS: Breton tampoco.

OP: Pero no porque creyese que Sartre tenía razón. Le pareció que aquello no tenía ni pies ni cabeza.

EMS: Pero no asumió la responsabilidad, por así decirlo.

OP: Es que en Francia había habido un abuso de la poesía, de desprecio a la poesía. La poesía no era significante. Había que verla desde 
un punto de vista simplemente estético, superior (lo que pensaba Valéry), o bien, como una expresión mística, de cierta realidad escondida, que eso sería el surrealismo. Olvidaban la ambigüedad esencial del acto poético y sobre todo, la ambigüedad esencial del lenguaje.

EMS: Creo que ése es el mérito singular de El arco y la lira. Para utilizar un concepto sartreano, le crea otra "situación" a la poesía; vuelve a situar a la poesía dentro de su verdadero contexto.

OP: Hay que decir que ya había antecedentes en Heidegger. De modo que este libro le debe no todo, pero sí algún capítulo central. No lo habría podido escribir sin Heidegger. Eso lo digo con mucha melancolía porque en ese momento ya se sabía que él había sido nazi; es decir, que había tenido simpatías nazis, aunque que habían sido transitorias. Yo no conocía bien la biografía. A mí lo que me impresionó de Heidegger, sobre todo, fue lo primero que leí de él en Cruz y Raya: “Qué es Metafísica?” Es un ensayo sobre la nada, extraordinario, y después leí, con mucha atención y con mucho cuidado, Ser y tiempo y las interpretaciones de varios otros, entre ellos la de José Gaos, pero no la única de este libro. En fin, un libro muy difícil, ahora le repruebo muchos aspectos. Me parece que es, a veces, inútilmente complicado.

EMS: Es muy alemán, entre otras cosas.

OP: Pero fíjate que Kant puede ser aburrido, pero no es despreciable. Me dijo un día Ortega y Gasset, quien tuvo simpatía por mí (pensó que yo no era totalmente estúpido): "Deje la literatura, deje la poesía y la literatura, póngase a pensar en serio y aprenda alemán, porque son las dos lenguas filosóficas, el griego y el alemán. Aprender el griego, a estas alturas, es un poco difícil, así pues, por lo menos alemán.” A mí me da tristeza porque creo que en lo de Heidegger hay una parte absolutamente perecedera, de mucho análisis. En ese momento yo no estaba familiarizado, tampoco, con la ciencia sino en términos muy generales, como buen hijo de mi época literaria. Había leído a Freud, esas cosas, pero la "ciencia ciencia" la conocía mal.

EMS: La física, por ejemplo.

OP: Todo esto, después de que lo he leído me ha asombrado. Heidegger era un enemigo de la técnica y la ciencia. Yo no lo soy. En el caso de Sartre y otros muchos, su ignorancia de la ciencia moderna es notable. Pero eso se puede extender a gente que tenía conocimientos científicos, como León Trotski. No sabía nada de matemáticas modernas, de la lógica moderna, estaba empeñado en la dialéctica, y no sabía que había una nueva lógica. Es decir, fui víctima un poco de las dos culturas: la cultura científica y la cultura humanística. Después lo he tratado de rectificar, no sé si lo 
he logrado. Las lagunas de ese libro pecan de por ahí. Sin embargo, lo esencial del libro lo sigo defendiendo. Aparte de que tiene algunas páginas que están más o menos bien escritas.

\section{Poema y pintura}

EMS: Has colaborado muchas veces con pintores. Esta colaboración entre pintor y poeta, ¿a qué se debe?

OP: A muchas cosas. En primer lugar, yo siempre tuve afición a la pintura. Bueno, tuve afición a todas las artes. Hemos hablado del descubrimiento de la filosofía moderna en el bachillerato, pero también hubo el descubrimiento de las artes. Claro, lo que pasa es que yo nunca me he sentido con autoridad para hablar de música, que es demasiado técnico, o de arquitectura, pero sí de las otras artes visuales, y propiamente de pintura. En mi caso, desde muy joven, me interesaron las artes visuales. Poco a poco han sido, en general, colaboraciones por amistad. Después, a los editores, algunos dueños de galerías, les ha interesado hacer esos libros de arte.

EMS: Por ejemplo, el de Cy Twombly, un libro muy hermoso.

OP: Yo no escribí nada, los poemas estaban escritos, pero él escogió los poemas y los ilustró.

EMS: Es uno de los pocos libros de arte tuyos que he podido adquirir. Uno de los últimos que me ha gustado mucho, que vi fugazmente, es el de Balthus. Lo vimos en Nueva York cuando estuvimos en el homenaje tuyo de la Academia de Poetas Norteamericanos.

OP: No lo he vuelto a ver. Es un libro muy bonito. Quiero mucho a Balthus. Soy viejo amigo, y de su mujer también. Los vimos ahora en París. Tiene 87 años.

EMS: Pero lo interesante es cómo éstas han sido coincidencias amistosas. Ciertamente lo fue en el caso de Tamayo.

OP: Ahí había más. Ahí había una defensa de Tamayo. Formaba parte de la lucha. Hemos hablado de esas luchas, que no son políticas, sino más bien de otro orden. Tiene que ver con la política. Tamayo había sido excluido del arte mexicano por los muralistas y por los críticos. Yo fui uno de sus primeros defensores.

EMS: Lo mismo ocurrió con Buñuel.

OP: Sí. Sobre Tamayo habían escrito Xavier Villaurrutia y algún otro. Pero nunca lo habían defendido. Lo habían exaltado como un pintor excelente y nada más. Yo fui el primero que me atreví a enfrentarme al 
dogmatismo de los muralistas y de los críticos. En el caso de Buñuel fue algo parecido, pero distinto. En Buñuel lo que pasa es que Los olvidados no fue enviada por el gobierno mexicano al festival de Cannes. No sólo eso: hubo mucha gente que criticó la película.

EMS: Porque daba una imagen "falsa" de México.

OP: Entre ellos, Fernando Benítez y...

EMS: La izquierda y la derecha unidos por el dogmatismo de la representación de México, de crear una "falsa imagen" de México.

OP: Yo admiré desde el principio a Buñuel: lo quise mucho y lo admiré mucho.

EMS: En el festival de Cannes, tú mismo repartiste las hojas de presentación.

OP: Sí, claro, él estaba muy enredado con eso. Había una correspondencia entre Buñuel y yo en ese momento. Después Buñuel pensó que yo podría hacer una película con él y no la hicimos: San Simeón, el Estilita, el asceta cristiano, ¿te acuerdas? Tengo una carta de Buñuel explicando por qué no colaboró conmigo en eso.

EMS: Krasno es otro pintor con quien colaboraste, ¿no?

OP: Bueno, Krasno menos. No pudo dar mucho. ¡Lástima! El libro que hicimos juntos fue idea totalmente suya. Yo no intervine para nada. En realidad, en ninguno intervine, en el sentido de que les dijera cómo había que hacer las cosas, pero habíamos escogido los poemas, o los textos, incluso en el caso de Tamayo. En el caso de Tamayo, ilustró ¿Águila o Sol? espontáneamente. Hizo tres dibujos que se han perdido: los ando buscando y no los encuentro. Tàpies también. Estos libros ilustrados por pintores les ayudan al poeta moderno a sobrevivir. A mí no tanto. Pero a muchos amigos míos, que no tenían entradas, les sirvieron muchísimo. Además, yo creo que es una tradición, eso sí me gustaría decirlo, de la pintura moderna. Hay antecedentes: Lope de Vega habló de pintura y Rubens de poesía. Pero esta colaboración entre pintores y poetas empieza, sobre todo, en la época del simbolismo. Empieza con Baudelaire, y luego, la continúan los simbolistas. Es sobre todo, una tradición francesa, que yo adopté y estoy muy contento de haberla adoptado.

\section{Poesía y cine}

EMS: También es interesante tu otra intervención directa en el cine. Has hablado en otras entrevistas, por ejemplo, acerca de tu fugaz trabajo con Jean Malaquais en esa lejana película El Rebelde con Jorge Negrete. 
OP: Es una adaptación de un cuento de Pushkin. Pero eso fue puramente potencial económico, alimenticio.

EMS: Sí, lo mismo de tu fugaz intervención como agente de doblaje de películas en Nueva York. Pero claro, nada de esto explica tan bien la fascinación que tú has sentido por llevar la palabra poética a la pantalla. Hace poco realizaste un impresionante video del poema Blanco y así cumpliste tu viejo sueño de hacer que la tecnología se ponga al servicio de la poesía. ¿Crees que lograste ese experimento en el video?

OP: Yo no puedo ser juez naturalmente. A mí me gusta, está bien hecho, con medios artesanales. Posiblemente se podría haber hecho mucho mejor. Pero creo que está bastante bien hecho y es una tentativa que ojalá tenga prolongación, no solamente en mi caso. Sería bueno que algunos poetas se arriesgaran a este tipo de experiencias. Después de todo se ha hablado muy mal de la televisión, pero yo creo que se habla mal por la manera en que la estamos usando. Podría ser un instrumento, como la radio, como los otros medios de comunicación, maravilloso.

EMS: Hay algunos desarrollos interesantes en la televisión norteamericana, o europea. Por ejemplo, con la cuestión esta que se llama mtv, la tv musical: canciones que se actúan, se dramatizan, presentan situaciones que yo al menos asocio con el surrealismo.

OP: Claro que los surrealistas se habrían quedado encantados. Lo que pasa es que todo eso se ha mercantilizado. El gran peligro es el mismo: son medios que se han transformado en grandes industrias. También la edición es industria, pero no de un modo tan directo como lo es la televisión y la radio. Pero quisiera añadir algo. Cada época tiene sus medios de comunicación. No sabemos cómo los primitivos decían los poemas. Probablemente los acompañaban con músicas, cantos y danzas, pero no sabemos cómo. Sabemos que los griegos recitaban los poemas. Yo he visto en la India cantar poemas, es una tradición. En fin, esto siempre ha ocurrido con los trovadores: el poema como palabra hablada. El poema como escritura aparece, por ejemplo, en la Edad Media: el libro ilustrado, las miniaturas. Con la imprenta todo cambia, pero no cambia totalmente. Cambia la manera de oír el poema; ya no lo oímos: lo leemos. Pero cuando lo leemos, lo oímos. Cuando tú lees un ensayo o una novela estás siguiendo, en el caso de la novela, las peripecias, o los análisis psicológicos, o las divagaciones del autor. Pero en el caso de un poema, no: tienes que leerlo y oírlo, aunque sea mentalmente, oralmente. Entonces, eso quiere decir que la poesía (y por eso Sartre estaba equivocado) ha conservado sus valores significativos. No es cierto que sea puramente sonoridad. Al mismo tiempo no rompe con los valores físicos, por ejemplo con el sonido, y hay también 
imagen poética. No todos los poemas, pero sí muchos, producen una imagen visual. En todos los poemas, de pronto, hay imágenes que tú ves con los ojos como ves una imagen en el cine, o un relámpago en el cielo de la noche.

EMS: Por eso, precisamente, el video de Blanco es tan impresionante. Logra captar ese paso que es, no precisamente intelectual, pero sí visual, sin abandonar el contenido referencial que se quiebra sobre todo con los colores.

OP: Ahí está. Lo que pensé siempre es que el cine y la televisión podrían ser buenos transmisores de poemas, pero que había que encontrar la forma. Blanco es una tentativa. Pero puede haber otras aproximaciones: no digo que sea la única. Lo que no me parece bien es la práctica norteamericana moderna de hacer que el poeta diga sus poemas en la televisión. Eso tiene interés, pero no mucho. Más interés tiene crear una obra que se desprenda. Yo creo que la obra poética debe desprenderse del autor. Aún la radio es muy importante porque está nada más la voz: no te molesta la presencia de un señor diciendo los poemas. Es lo que traté de evitar también en Blanco.

EMS: No hay personajes.

OP: Hay frases, imágenes y sonidos.

EMS: Y alguna que otra letra.

OP: Sí, y letras. De hecho, podría haber usado más letras, pero era muy difícil. Quizá en otra pantalla más grande hubiéramos podido utilizar más letras, en movimiento, quizá. Una de dos: o se extingue, pero entonces sería una pérdida muy grande para la poesía, o bien la poesía logra introducirse en los nuevos modos de comunicación. En ese caso, inaugura un porvenir muy distinto al resto de la literatura. Porque la novela hoy día se convierte en telenovela, en soap opera. Yo no sé qué va a ocurrir con la novela. Mientras que en el caso de la poesía, puede cambiar, como el ejemplo que tú pusiste de la música visualizada.

\section{Poesía e historia}

EMS: Hace cuarenta años escribiste y publicaste El arco y la lira. Pero hace ya casi cincuenta publicaste El laberinto de la soledad, donde describiste, y criticaste, un país y una gente.

OP: Bueno, México.

EMS: Sobre todo, lo que toca al trato entre las personas. Después de haber hecho una edición de El laberinto de la soledad, después de haber 
pensado en ese libro, una de las cosas que siempre me ha impresionado acerca de ese libro es que es un lamento acerca de cómo la gente se trata.

OP: No creo que sea un lamento.

EMS: Al menos una crítica. Una descripción.

OP: Es una descripción del trato en una sociedad. Es un libro sobre una sociedad. Una sociedad no es lo que piensan los hombres únicamente, lo que hablan y piensan entre ellos. La palabra entre es fundamental porque la sociedad es relación sobre todo y la palabra entre es, sobre todo, eso: relación. A veces relación de oposición, a veces de afinidad. Porque soy mexicano: no podía describir otro país. Mexicano de una clase social y de una región. Hay partes de mi libro que seguramente no se aplican a los campesinos mexicanos, o a los indios de Oaxaca, o de Chiapas. En otros ensayos me he ocupado de ellos y sobre todo, de sus antepasados, de historia del arte por ejemplo. Me ha interesado mucho el mundo precolombino. Creo que soy el escritor mexicano que ha escrito más sobre el mundo precolombino: más de la mitad de mi libro Los privilegios de la vista es sobre arte precolombino y sobre la sociedad precolombina. Pero son estudios más bien históricos.

EMS: Mientras que El laberinto de la soledad...

OP: Es una descripción viva, de la cual soy testigo.

EMS: Me da la impresión que el libro surge de una angustia, aunque para ti era evidentemente una falta de relación.

OP: Bueno, lo que es, sigue siendo, una falta de relación, perversa o dañina. Una relación, como todas las relaciones, hechas de amor y de odio, de miedo y de descubrimientos. Es lo que quise expresar. Cuando escribí el libro me di cuenta de un tema esencial: los hombres están solos. Es un tema universal. Y los hombres quieren remediar su soledad de muchas maneras. El ermitaño no existe, el ermitaño es un fenómeno aislado. Incluso cuando se aísla, el ermitaño lo es porque atrás está la comunidad. De modo que el hombre es siempre un ser comunitario. Las comunidades humanas son imperfectas y están movidas por este doble ritmo de unión y separación. Y en este caso, en México, esto es particularmente cierto. México es un fragmento de la historia universal. México como nación, como país, nació cuando se quebró el imperio español. El mundo precolombino no conoció al otro: se conocían ellos mismos. Era una sociedad cerrada sobre sí misma, dividida en distintas naciones que guerreaban sin cesar. Esto es lo mismo aplicable a las altas civilizaciones de México como a las planicies de los nómadas de Estados Unidos, donde hubo guerra continua entre ellos. La colonia española, la dominación española, resuelve esto en una unidad. Por una parte unidad política, el Virreinato: por la 
fuerza e impuesta. Por otra, unidad religiosa: no solamente impuesta sino adoptada por los nuevos creyentes. Después, México se convirtió en una nación católica. Pero el catolicismo dejó de operar, y en el siglo diecinueve ocurren dos cosas. Una es la gran ruptura, a fines del dieciocho, principios del diecinueve: la gran dispersión, la gran fragmentación de España. Surge en todos estos países de América Latina. Uno de ellos es México, que quiere buscar o encontrar una nueva universalidad, una nueva manera de insertarse en el mundo. La otra es la soledad, no solamente la soledad de cada miembro, de cada mexicano, sino también de la colectividad del país. Y creo que es aplicable a toda América Latina.

EMS: Yo leo el libro en un curso que doy sobre Literatura y Sociedad en América Latina. Comenzamos con El laberinto de la soledad como una introducción a América Latina, no sólo a México.

OP: ¿Cuál es la reacción de los jóvenes?

EMS: Se quedan deslumbrados. En la universidad norteamericana los estudiantes están habituados a dos cosas: o bien, a leer literatura, o bien historias oficiales. Tu libro es distinto: un ensayo literario que va dando opiniones acerca de cosas extrañas: los "pachucos" de Los Ángeles, reflexiones acerca de La Malinche y Hernán Cortés. En general, el libro toca una estructura profunda.

OP: Hay otros elementos que no aparecen en otros países. Por ejemplo, el mundo precolombino no aparece en Argentina, en Cuba apenas. En Cuba lo que aparece es el elemento negro.

EMS: Claro. Pero en última instancia, eso no es lo importante. Lo importante es la soledad del ser humano, sobre todo en una situación en la que la modernidad, en vez de resolver ese problema, lo agrava. Ése es el fenómeno de América Latina.

OP: Y no hemos podido todavía insertarnos en la modernidad. Al contrario.

EMS: Lo que hemos hecho es tratar de resolver el problema complicándolo a partir de otro concepto manipulado: la modernización.

OP: No somos los únicos. Sin hablar de los países asiáticos, sin excluir a Japón que también tiene grandes problemas íntimos, digamos un ejemplo europeo, o casi europeo: Rusia. Los rusos, ahora lo estamos viendo después de setenta años de comunismo, no acaban de ser modernos.

EMS: Pero también creo que el argumento tuyo es doble. México, afortunadamente, no se ha podido insertar completamente en la modernidad porque su premodernidad de alguna manera lo salva. La modernidad tampoco es la solución.

OP: Nos ha preservado, pero evidentemente no es una respuesta. 
EMS: ¿Hay respuesta?

OP: El mundo ha cambiado. Hay problemas ahora que no existían hace cien años.

EMS: El tráfico, por ejemplo.

OP: Yo estaba pensando en el polumo. Eso no existía. Pero, de todos modos, esto es consecuencia de la historia de México. No había tampoco sobrepoblación. Era un país con pocos habitantes y ahora tiene más de cien millones. Los problemas se han agravado. Lo esencial es el gran problema de la convivencia. Primero entre los mexicanos, y frente al mundo: sigue siendo la gran interrogación de México.

EMS: En ese sentido, creo que el libro es vigente. Es decir, todavía hace las mismas preguntas que todo el mundo se hace y no se pueden responder fácilmente.

OP: Solamente que seas un fanático y tengas una respuesta a todo eso. La Iglesia católica lo dice así. También el Partido Comunista: ellos tienen la solución y a los que no estén de acuerdo hay que fusilarlos.

EMS: Tú tienes, de hecho, el raro privilegio de ser el único escritor y, que yo sepa, la única figura pública que ha sido quemada en efigie en México. Lo más terrible es que desde que ocurrió, en 1984, nunca ha habido ninguna retracción, o siquiera una reflexión, sobre este acto.

OP: Así es. En el momento en que esto ocurrió yo estaba fuera de México. Muy pocos protestaron, no llegaron a diez. Después, nadie ha dicho ni media palabra. Cuando recuerdo esto, o cuando alguien lo recuerda, hay una incomodidad generalizada, un poco como decir "calzones" en la sociedad burguesa de fines de siglo: palabras inconvenientes. Eso confirma El laberinto de la soledad. Nuestra incapacidad para aceptar la realidad.

EMS: Pero también tiene un aspecto institucional que a mí por lo menos me indigna. Hoy en un taxi pasé frente al Museo Nacional de Antropología. Pensé en la "crítica de la pirámide”, en el ensayo Postdata y en la crítica que le hiciste al museo en ese momento, la falsificación de la historia de México. Me preguntaba entonces: ¿habrán los científicos de inah rectificado, o reflexionado, sobre esa crítica de una persona que, con buena fe, ha hecho una observación sobre su tarea? Me entró una melancolía terrible al pensar que la sordera todavía existe a ese nivel institucional.

OP: Sí, existe sobre todo entre los intelectuales, y en el medio oficial. Hay otros ejemplos de esta suerte de incapacidad, no sé cómo llamarla. Por ejemplo, el arzobispo de México hace unos meses condenó el libro mío sobre Sor Juana Inés de la Cruz porque le parecía blasfemo. 
EMS: ¿Sin haber hecho una reflexión?

OP: Pero, además, él no tiene autoridad para hacerlo. El pobre arzobispo que hable de otras cosas. Pero no tiene autoridad ni literaria ni histórica para hablar de esos temas. Los otros, sus acólitos, un teólogo y un historiador, presentaron argumentos tontos.

EMS: El problema no es que no tengan el derecho a hacer cualquier tipo de observación. Lo tienen. Pero ¿está sustentada esa observación en una reflexión o en un argumento racional, lógico?

OP: Hay que decir, y esto te da otra visión, que en el caso del arzobispo hubo muchas respuestas de intelectuales. Dijeron que aunque no estaban de acuerdo con mi visión de Sor Juana, era intolerable que el arzobispo hablara de esto. Pero esas mismas personas no dijeron ni media palabra cuando me quemaron en efigie, en el Paseo de la Reforma, o cuando ha habido otros escándalos por el estilo. Todo el tiempo hay pequeños olvidos en mi ciudad. No me gusta hablar de eso porque parece que tengo obsesión.

EMS: Sé que evitas el tema. Pero yo no lo puedo obviar. Al hacer una observación acerca de, por ejemplo, Octavio Paz en su contexto, estas cosas hay que decirlas.

\section{La soledad}

OP: Además se ha difundido la visión de que yo soy un hombre autoritario. Tú que me conoces sabes muy bien que no lo soy, que si algo soy es un hombre que duda de sí mismo sobre todo, de lo que pienso y de lo que digo. Hablemos del malestar, puesto que hemos hablado de $E l$ laberinto de la soledad. Hablemos de mí mismo. Porque hay una parte de autobiografía en ese libro, como en todo libro de esa índole. Desde niño me sentí excluido; por razones misteriosas, pero siempre me sentí excluido. No sé si los demás niños sintiesen lo mismo, creo que no. Yo me sentí siempre excluido, aparte. Y eso ha continuado hasta ahora. "No es mexicano", me acuerdo que me decían. Durante años me criticaron con la idea de que yo no era mexicano, que yo era un extranjerizante, que era un eco de Francia, o de los Estados Unidos, de lo que fuera, que no era de aquí. Después, que yo era un escritor difícil, intelectualista, que yo no era poeta, que nadie me entendía, que no era un poeta que se pudiera entender.

EMS: Si no se comprende eso acerca del contexto de Octavio Paz, se pierde gran parte de la esencia de tu preocupación. Primero, por la evidente introspección de tu poesía: ese tono íntimo de diálogo con el otro, de establecer un diálogo con el otro, aunque sea el otro que se lleva 
dentro. Y después, la pregunta obsesiva acerca de México, acerca de tu cultura y tu tiempo.

OP: Eso es natural. Después de todo, cuando hablábamos de esa situación mía, de ser una suerte de islote, señalado con reprobación o con desconfianza o con lejanía, hay que decir que se trata de un mundo muy pequeño: a la mayoría de los mexicanos ni lo saben ni les importa, ni mucho menos. Pero es el pequeño mundo en el que vivo.

EMS: A lo que me refiero es a esa misma imagen dentro de tu literatura. Por ejemplo, el primer texto de Libertad bajo palabra: un "pueblo rencoroso" que te acusa, el "bullicio" contra el cual surge la palabra.

OP: Hay silencio. Nadie quiere hablar de eso, porque si se habla de eso hay que decidir si yo soy un enfermo mental, o si tengo delirio de persecución.

EMS: $O$ si eres un caudillo que persigue a los demás.

OP: Algo así. Si bien hay algo de verdad en lo que yo siento y en lo que yo digo, es lo que no han dicho nunca.

EMS: Tal vez porque no hay una reflexión.

OP: Sí. Y esto incluso con gente que quiero y estimo. No ha habido ninguna tentativa por hacer ese tipo de reflexión.

EMS: Y lo interesante es que a pesar de eso estás aquí al pie del cañón. No te has ido a vivir al extranjero, sólo por temporadas.

OP: Bueno, viví muchos años fuera. Regresé después del 68. Regresé primero porque quería terminar dos diálogos. Primero, el diálogo con mi madre: resultó que era ya muy mayor y no pude terminarlo como yo hubiese querido. Y después, el diálogo con mi país. Ese terminó en una querella que aún no se cicatriza.

EMS: ¿Y ha terminado el diálogo?

OP: Lo que pasa es que ya no hay diálogo. Es innecesario, no puedo seguir argumentando.

EMS: ¿Has dicho todo lo que tienes que decir?

OP: He dicho no todo, pero sí casi todo. Quizá tendría que haber escrito una obra de ficción para poder decir con mayor facilidad muchas cosas que no dije, o dije mal. Nunca está uno satisfecho con lo que se ha dicho. Hace mucho escribí El laberinto de la soledad, no sé siquiera si lo tolero ahora. Pero creo que aunque mi país ha cambiado, el análisis sigue siendo válido.

\section{¿Obra completa?}

EMS: Quisiera terminar hablando de la edición de tus Obras completas, que va a publicar Círculo de Lectores. 
OP: Se está terminando ya. Estamos en el tomo décimo.

EMS: Para mí es impresionante esta reordenación de tu obra.

OP: Yo simplemente lo he agrupado de un modo bastante sencillo, por temas.

EMS: Pero también es una relectura de tu obra.

OP: No creas. He agrupado los libros porque más o menos sé de qué tratan.

EMS: ¿Por temas, pero no cronológicamente?

OP: No, pensé, dudé entre cronología y temática.

EMS: $Y$ triunfó la temática.

OP: Sí, porque si hubiese hecho una ordenación puramente cronológica, habría sido de lectura muy difícil. Puede que sea un poco monótono. Pero ahí, en las primeras quinientas o seiscientas páginas, está lo que yo llamaría, con un poco de exageración probablemente, mi poética. Después, en los tres tomos siguientes está mi crítica literaria, que es sobre todo crítica poética y que también tiene que ver con mi formación. Casi nada de lo que he escrito es puramente desinteresado, aunque muchos de esos textos sí fueron pedidos por amigos o por editores, o por revistas. Probablemente nunca habría escrito sobre Rubén Darío si no me lo hubieran pedido. Pero estoy contento con lo que hice sobre otros. Después, está el tomo sobre Sor Juana, que lo continúa: es crítica literaria, pero también es un libro de historia y una biografía. A mí lo que me gusta de ese libro es la parte final; con la parte primera, que es puramente biografía, habría podido escribir una novela. Después los dos tomos de artes visuales, donde hay algunos ensayos que me gustan; luego el tomo sobre temas mexicanos. Y luego el décimo tomo, la reflexión, donde están algunos de los libros que más me gustan.

EMS: Vislumbres de la India, por ejemplo.

OP: Ése me gusta menos, aunque tiene capítulos que me gustan. Me gusta mucho más el pequeño ensayo sobre Sade. Ahí digo cosas que creo son relativamente nuevas. Hace cuatro o cinco meses, en una revista universitaria salió un ensayo largo de un profesor sobre el Marqués de Sade. Cita a casi todos los que han escrito sobre el tema, menos a mí. Pero ahora lo que me interesa es la poesía. Luego incluiremos en otro tomo entrevistas como ésta, porque creo que forman parte de mi obra, de mi actividad literaria. Algunas, no todas. Pero no creo yo mucho en las Obras completas. Están bien que se queden ahí, pero lo que puede que quede de las obras serán algunas páginas. Con eso basta.

Me gustaría, por último, hablar un poco de mi experiencia de la India. Quisiera hablar un poco de dos cosas. De mi experiencia en el 
extranjero, el descubrimiento de los Estados Unidos, por ejemplo. Conocí al país de niño, fue un espectáculo magnífico.

EMS: Por una parte, Tú como el Otro dentro de México; pero después el Otro dentro de otra cultura. Primero los Estados Unidos, aunque tal vez primero fue España.

OP: Eso es lo que quisiera decir: mi relación con España siempre ha sido muy profunda. Me siento, yo siento, que soy heredero de la gran literatura española. ¡Y que no me griten los españoles creyendo que ellos son los dueños de Cervantes, o de Quevedo o de Góngora, porque no lo son! Es un bien compartido. A los Estados Unidos los conocí en plan de guerra: el trabajo, el valor, un pueblo de gente valiente, abierto, hospitalario, generoso. Francia fue reencontrarme con mi adolescencia, con mis lecturas. Fue un momento también de grandes pasiones. Finalmente en la India lo más importante que me pasó fue haber encontrado a Marie-José. Porque esto cambió radicalmente mi vida. Sin ella yo no hubiera podido hacer mucho de lo que he hecho.

EMS: Sobre todo después que te vas de París en 1962 y de padecer la gran decepción que cuentas al final de Salamandra, en el penúltimo poema: "Yo estaba vivo y fui a buscar la muerte". Haberte ido a la India como una especie de adiós a todo, para después llegar allí y encontrarte con la vida, con esa maravillosa mujer, todo eso tiene que haber sido algo muy grande pero también muy extraño. Ir al otro extremo del mundo para encontrarte a ti mismo.

OP: Yo creo que una vida humana (y aquí podemos terminar) está hecha de muchos nacimientos, muertes y renacimientos. No es cierto que uno nazca una sola vez. No sé si se nace una sola vez, pero sí sé que se muere y se renace muchas veces, hasta que nos toque la definitiva.

EMS: Eso lo aprendí leyendo tu obra, sobre todo leyendo tu poesía. Esa necesidad de reconocer cuándo algo termina y cuándo se debe volver a empezar. Como te ocurrió en 1943, cuando escribes La vida sencilla.

OP: ¡Ah, ese poema te gusta!

EMS: Es con el que cierro el prólogo a tus Primeras Letras.

OP: También ahí hay el comienzo de algo que no se sabe.

EMS: La puerta condenada con que...

OP: ....se dice adiós a México.

EMS: Sí, el adiós a México y el saludo a otro tipo de relaciones.

OP: A otro tipo de poesía... y de vida. 